\title{
Small-Size Eight-Band Frequency Reconfigurable Antenna Loading a MEMS Switch for Mobile Handset Applications
}

\author{
Xin Meng ${ }^{1,2}$ \\ ${ }^{1}$ School of Electronic Information Engineering, Tianjin University, Tianjin 300072, China \\ ${ }^{2}$ School of Computer and Communication Engineering, Tianjin University of Technology, Tianjin 300384, China \\ Correspondence should be addressed to Xin Meng; meng_tjut@163.com
}

Received 7 March 2014; Revised 16 April 2014; Accepted 18 April 2014; Published 13 May 2014

Academic Editor: Yingsong Li

Copyright (c) 2014 Xin Meng. This is an open access article distributed under the Creative Commons Attribution License, which permits unrestricted use, distribution, and reproduction in any medium, provided the original work is properly cited.

\begin{abstract}
A planar small-size eight-band frequency reconfigurable antenna for LTE/WWAN mobile handset applications is proposed. The proposed antenna consists of a feeding strip and a coupled strip, with a total dimension of $10 \times 29.5 \mathrm{~mm}^{2}$. Reconfigurability is realized by incorporating a one-pole four-throw RF switch, which is embedded in the coupled strip and changes the resonant modes for the lower band. By combining four different working modes, the proposed antenna successfully realize the eight-band operation, covering the operating bands of 700 787 MHz, 824 960 MHz, and 1710 2690 MHz. In addition, the simple DC bias circuit of the RF switch has little effect on the antenna performances, with no significant reduction in antenna efficiency and variations in the radiation patterns. The measured antenna efficiencies are $40 \%$ $50 \%$ and over $60 \%$ for the lower band and the upper band, respectively. Prototypes of the proposed frequency reconfigurable antenna incorporating the one-pole four-throw switch are fabricated and measured. The measured results including return losses and radiation characteristics are presented.
\end{abstract}

\section{Introduction}

Portable devices with wireless connectivity have experienced a rapid growth in the last decade, which also face the great challenge to cope with various wireless standards (WIFI, Bluetooth, GPS, and GSM) with a wide bandwidth. For further portability and better user experiences, the size reduction has been a trend in the wireless system designs. Nevertheless, designing an internal multiband antenna for mobile handsets within a small size is still full of challenges.

To reduce the antenna size and achieve wide bandwidth, a great deal of methods have been proposed, such as the couple-fed method referred in [1-4], the parallel resonance method used in [5], and the distributed inductor proposed in $[6,7]$. For further size reduction, these traditional wideband methods with single working state are limited. Considering the limited space for antenna design for mobile handsets, reconfigurable technology [8-17] is a good candidate. By using the reconfigurable technology, the antenna can work in several states to obtain wide bandwidth with a reduced size. Commonly, the reconfigurability is achieved by RF MEMS switches [8-11], PIN diodes [11-15], and varactors [16, 17].
Reconfigurable antennas loading PIN diodes referred in [1315] have significantly reduced the sizes of the multiband antennas, and they have also been proved with acceptable insertion losses. However, the PIN diode usually acts as a resistance, while larger $\mathrm{dc}$ power is required to gain lower insertion loss in practical applications. From this respect, the MEMS RF switches referred in [8-12] are more practical, which have much lower insertion losses [11] and smaller effect on the radiation characteristics as well as lower costs in comparison with the PIN diodes.

In this paper, a printed frequency reconfigurable antenna with a one-pole four-throw RF switch loaded for eight-band WWAN/LTE mobile handset applications is proposed. The reconfigurable antenna comprises a simple structure of a feeding strip, a coupled strip, and a one-pole four-throw RF switch as well as its DC bias circuit. The RF switch works in four different states and changes the resonant modes through modifying the values of the lump inductors. By combining the four different states, the proposed antenna successfully covers the eight-band operation of GSM850/900/1800/ 1900/UMTS2100/LTE2300/2500. With a total size of $10 \times$ $29.5 \mathrm{~mm}^{2}$, the proposed antenna is much smaller in contrast 


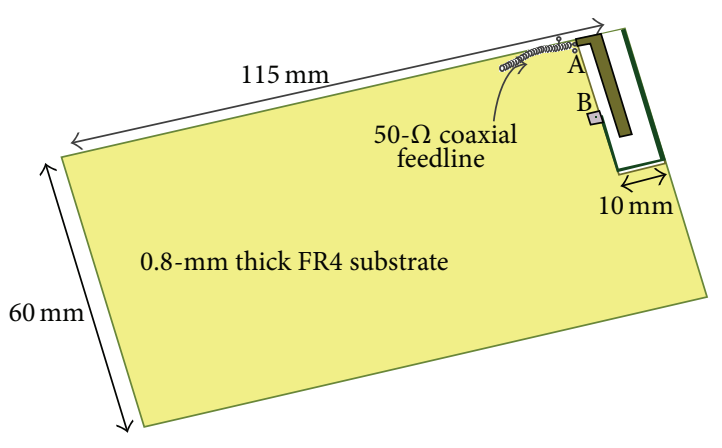

(a)

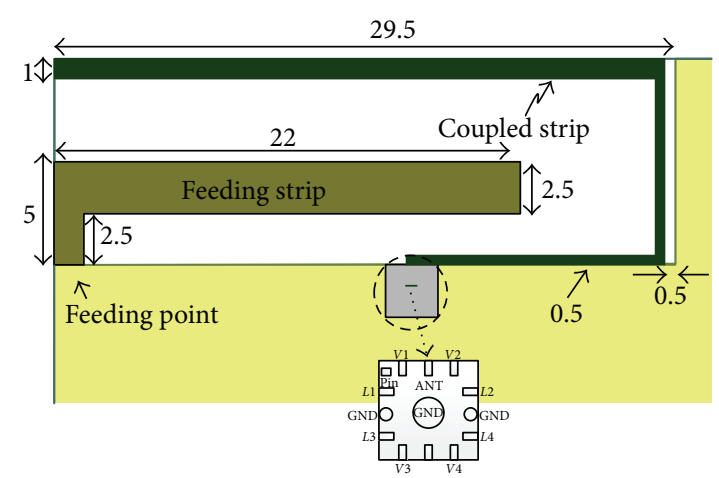

(b)

Figure 1: Proposed reconfigurable antenna configuration. (a) Geometry of the frequency reconfigurable antenna. (b) Detailed dimensions of the reconfigurable antenna $(L 1=6.8 \mathrm{nH} ; L 2=9.2 \mathrm{nH} ; L 3=15 \mathrm{nH} ; L 4=17 \mathrm{nH}$; GND: ground point $)$. All dimensions are in millimeters.

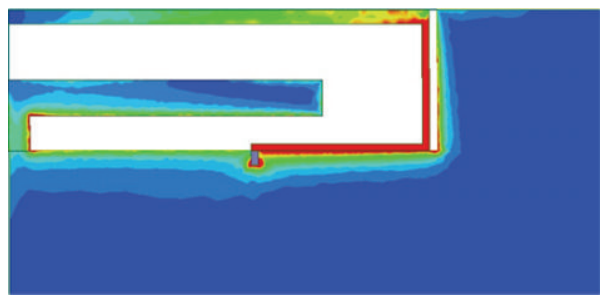

(a)
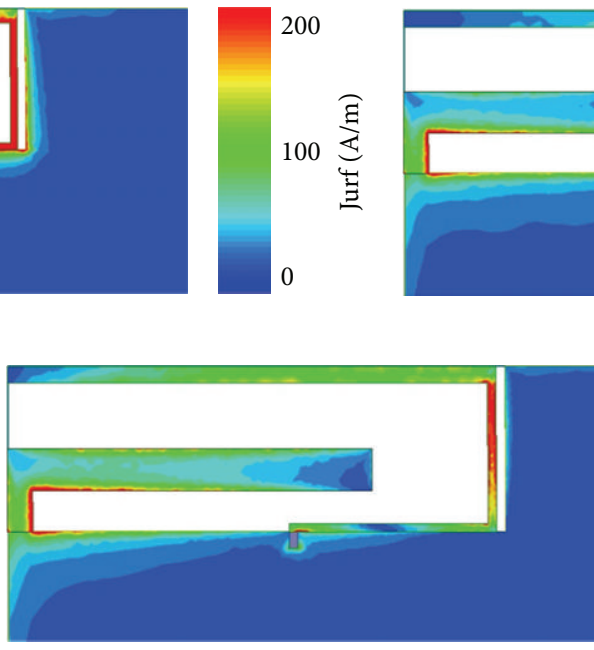

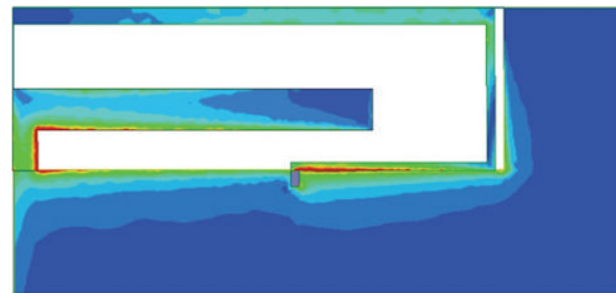

(b)

(c)

Figure 2: Simulated current distributions at different frequencies. (a) $925 \mathrm{MHz}$; (b) $1850 \mathrm{MHz}$; (c) $2470 \mathrm{MHz}$.

to the antenna referred in $[12,14]$. Moreover, compared to the antenna in [5], the proposed antenna has a smaller size and an extra coverage of LTE700 operation, which is mainly due to the combination of four different working states of the RF MEMS switch. Although the insertion of the RF switch may exert influences to the antenna performances, the effects such as insertion losses and the impedance matching are quite acceptable and proved practical for mobile handset applications [11], considering the great benefits of minimization and band expansion with the incorporation of the RF MEMS switch. Fabrication of the printed reconfigurable antenna is easy and its cost is low, while the antenna has good performances and small insertion losses. Measured radiation characteristics of the proposed reconfigurable antenna are presented.

\section{Proposed Reconfigurable Antenna}

Figure 1(a) depicts the geometry of the proposed antenna, which has a total size of $10 \times 29.5 \mathrm{~mm}^{2}$ and is printed on a $0.8 \mathrm{~mm}$-thick FR4 substrate with relative dielectric constant of 4.4 and loss tangent of 0.02 . The frequency reconfigurable antenna consists of a coupled-fed antenna and a one-pole four-throw RF switch and its corresponding DC bias circuits. Detailed dimensions of the printed antenna and the onepole four-throw RF switch are given in Figure 1(b). The coupled-fed antenna comprises a feeding strip and a coupled strip, while the coupled strip is grounded through the RF switch. Furthermore, the RF switch is located within the dotted line as shown in Figure 1(b), and its ground (GND) pins are connected with the back-side system ground via metallized holes. The embedded inductors are controlled by the corresponding DC bias voltages $(V 1, V 2, V 3, V 4)$ and only one inductor is involved in each working state with other inductors unoccupied. For example, when $V 1$ is supplied with high voltage and the other three ports are in low level, then the lumped inductor $L 1$ is incorporated and the antenna works in the state of $L 1$.

In the proposed antenna, the monopole feeding strip contributes a resonant mode at about $1850 \mathrm{MHz}$, while the other 


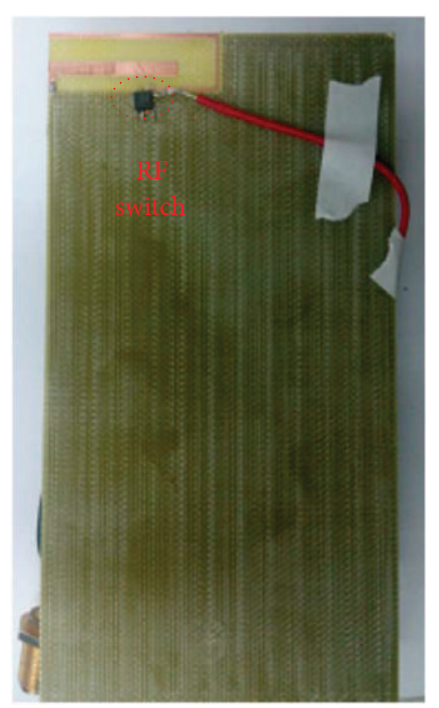

(a)

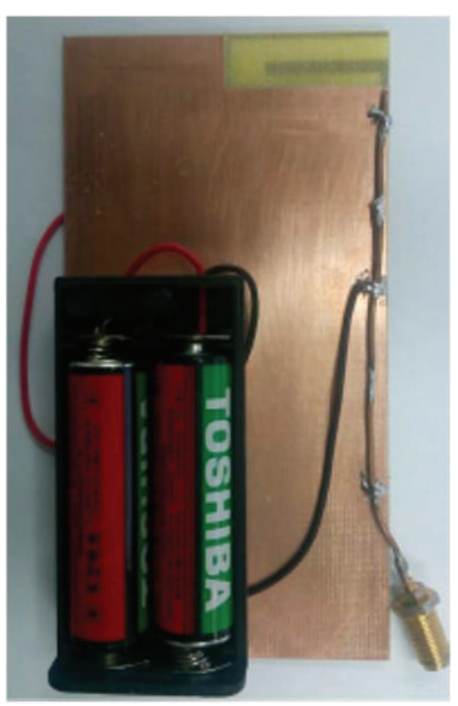

(b)

FIgURe 3: Photos of the manufactured reconfigurable antenna for eight-band mobile handset applications.

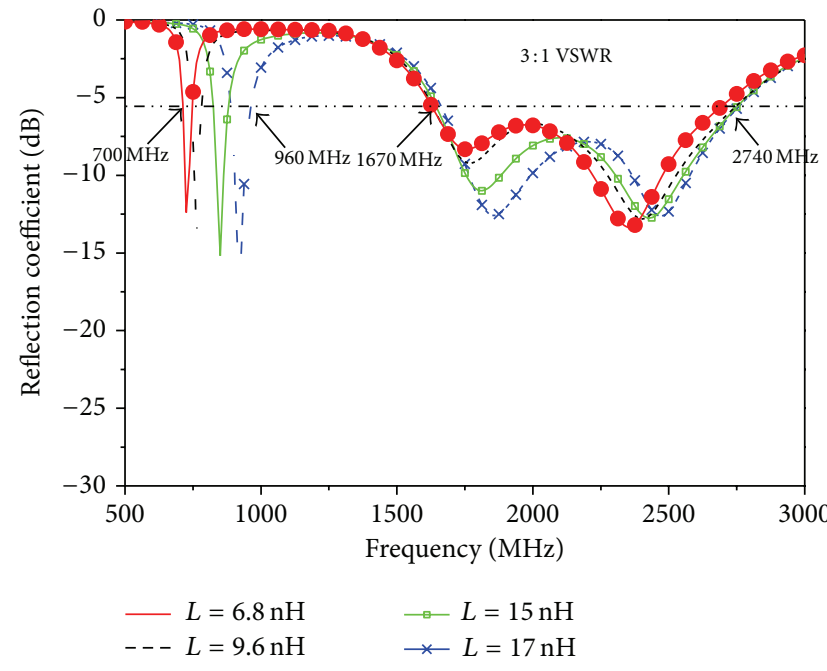

(a)

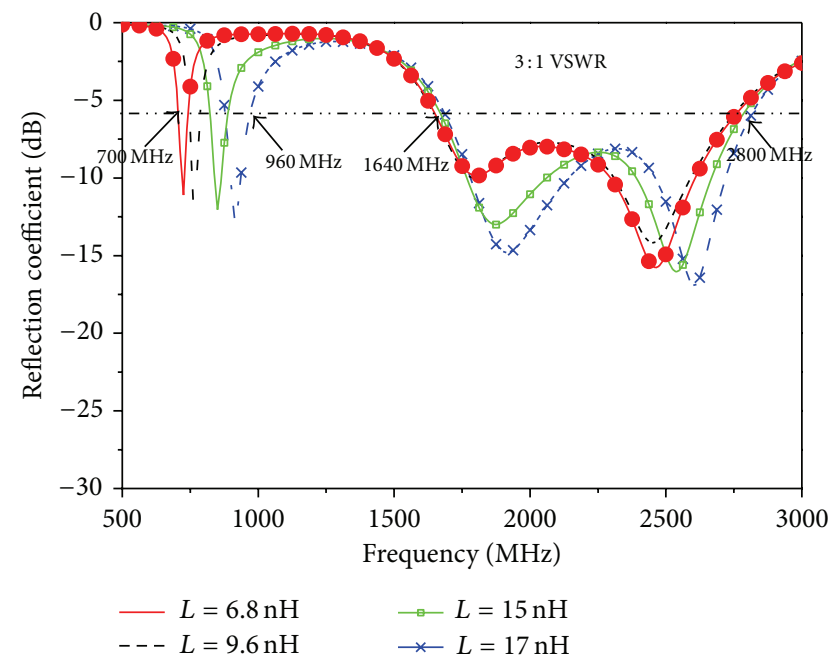

(b)

FIGURE 4: Simulated and measured reflection coefficient against frequency for the proposed antenna. (a) Simulated results. (b) Measured results.

resonant mode is generated by the coupled strip at about $2470 \mathrm{MHz}$ for the upper band. Therefore, a wide bandwidth is achieved by combining the two resonant modes, covering the GSM1800/1900/UMTS2100/LTE2300/2500 operation. One resonant mode is contributed by the coupling strip for the lower band. In particular, the referred one-pole four-throw RF switch is applied to modify the resonant frequencies, which can effectively expand the coverage by combining four different working states. Actually, the optimization process of the antenna is not so easy, which needs to meet the requirements of impedance matching in different states. Specially, the RF switch is located in the shorting point of the coupled strip and there is little influence on the upper band when the working state is switched. Then the reconfigurability is finally realized to cover the LTE700/GSM850/900 operation.

Figure 2 shows the simulated current distributions for the proposed antenna at the resonant frequencies of $925 \mathrm{MHz}$, $1850 \mathrm{MHz}$, and $2470 \mathrm{MHz}$. For clear explanation, only the state of $L=6.8 \mathrm{nH}$ is selected for the lower band. As shown in Figure 2(a), the current distributions on the coupled strip are much stronger, suggesting that the resonant mode at about $925 \mathrm{MHz}$ is mainly contributed by the coupled strip. With the same principle, the other three resonant modes for the lower band can be explained. From Figure 2(b), it can be seen that strong current flows along with the feeding strip and the coupled strip, confirming that the feeding strip 

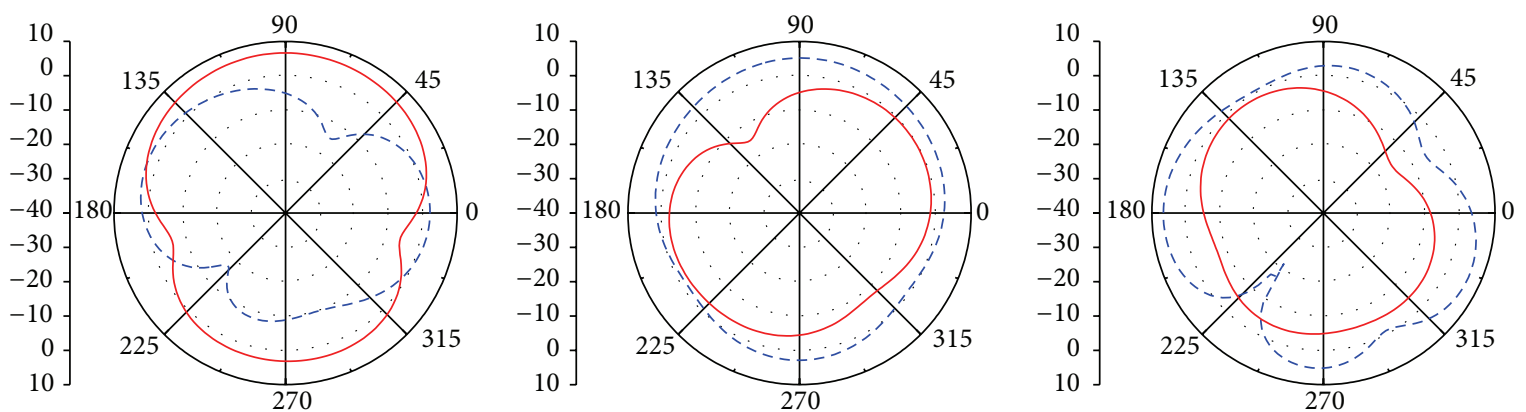

(a)
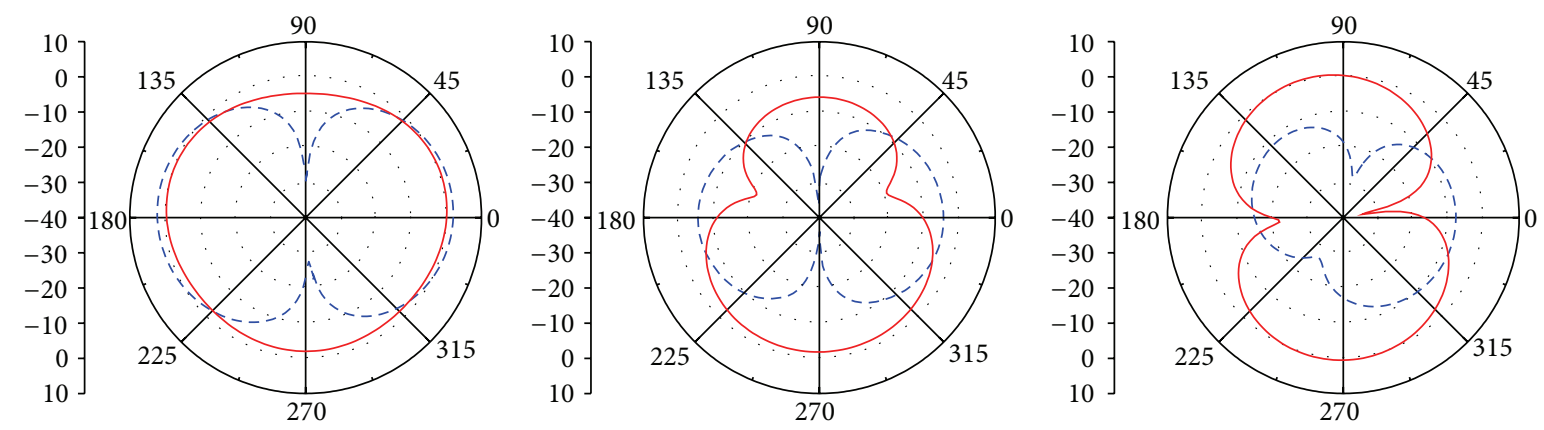

(b)
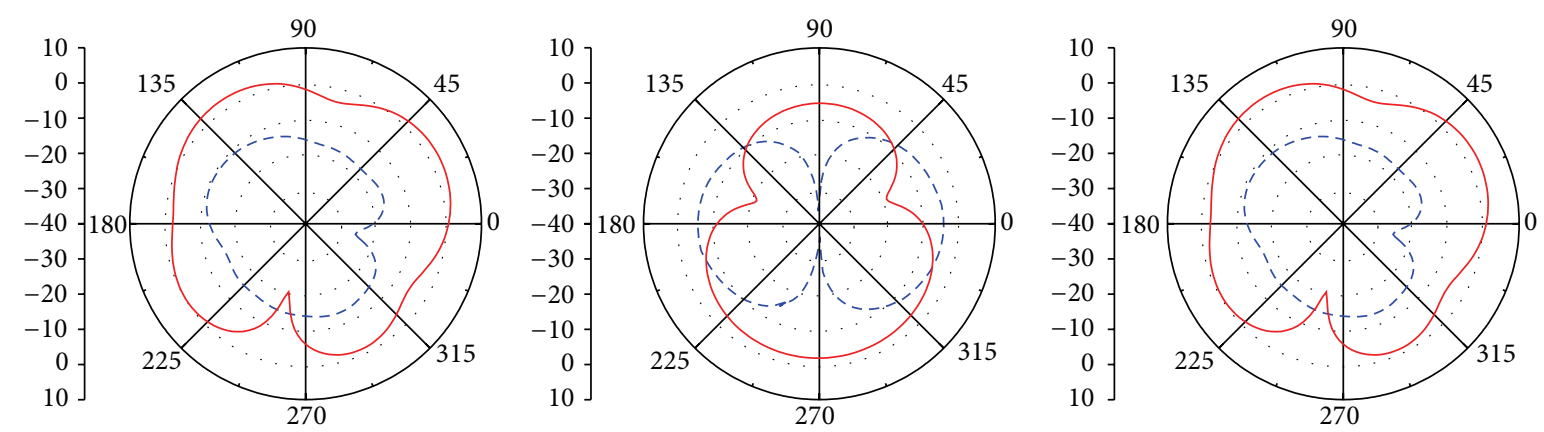

(c)
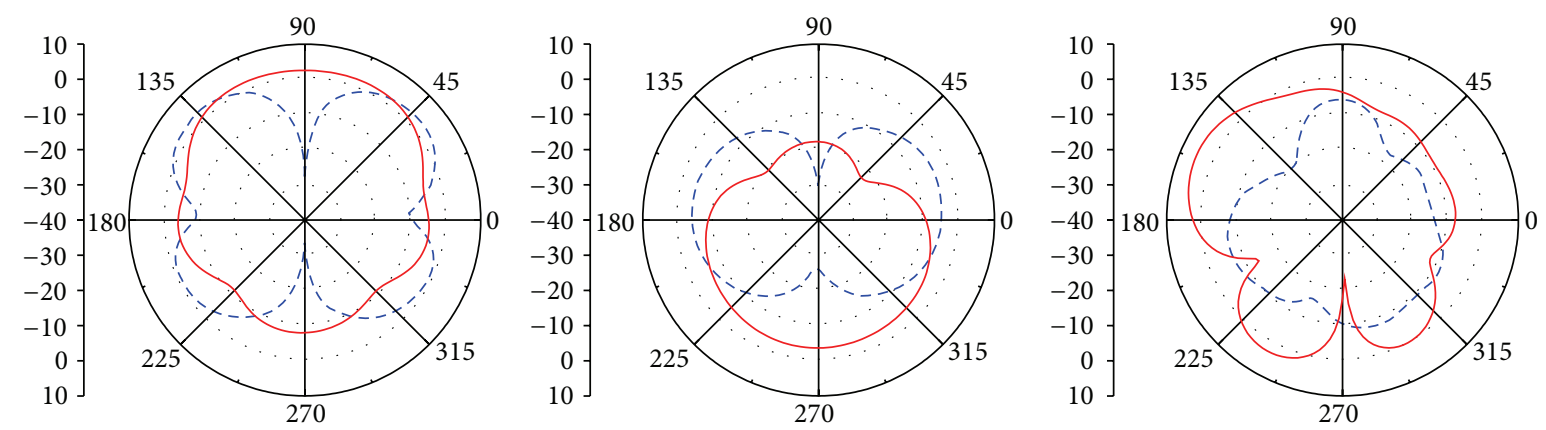

(d)

Figure 5: Measured 2D radiation patterns. (a) $750 \mathrm{MHz}$; (b) $925 \mathrm{MHz}$; (c) $1925 \mathrm{MHz}$; (d) $2350 \mathrm{MHz}$ for the proposed filtering antenna (- - . - - $\left.E_{\varphi},---E_{\theta}\right)$. 


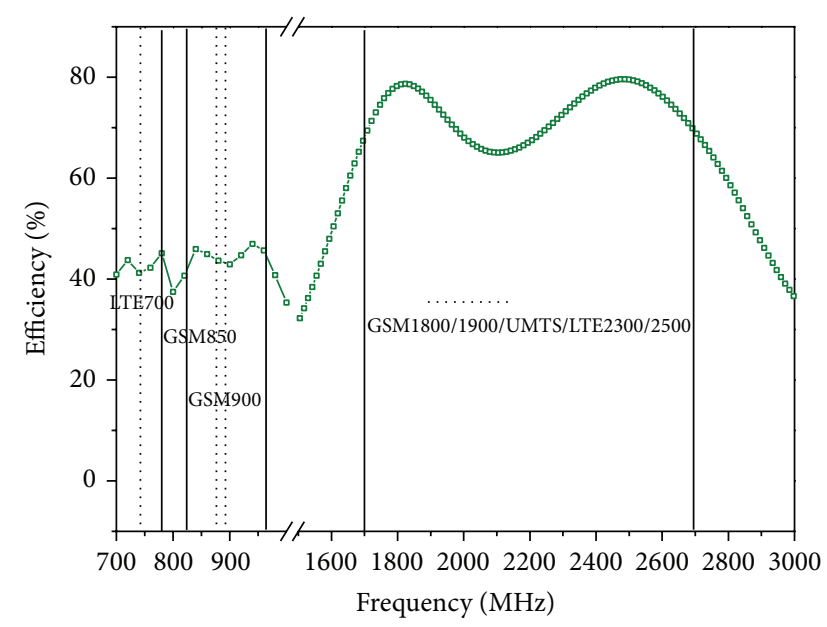

FIGURE 6: Measured antenna efficiencies (mismatching losses included) against frequency for the proposed antenna.

contributes much for the resonant mode at about $1850 \mathrm{MHz}$. Figure 2(c) depicts that the strong current distributions are on the coupled strip, proving that the resonant mode at about $2470 \mathrm{MHz}$ is generated by the coupled strip.

\section{Results}

The proposed printed reconfigurable antenna was fabricated and tested. Photos of the fabricated antenna and the onepole four-throw RF switch (FMS2016QFN-1) as well as its corresponding DC bias circuits are shown in Figure 3. The simulation and optimization of the reconfigurable antenna are based on the HFSS 12.0, and the measured results are obtained by using the network analyzer and the Satimo StarLab far field measurement system. The simulated and measured reflection coefficients against the frequency for the four working states are plotted in Figure 4 with good agreement, and little effect is found for the upper band when the state of the RF switch changes. The DC bias voltage is supplied by two AAA batteries, and the working state can be switched by changing the voltage level of different ports $(V 1, V 2, V 3, V 4)$. By combining the four working states, the reconfigurable antenna successfully covers the LTE700GSM850/900/1800/1900/UMTS2100/LTE2300/2500 operation.

Measured radiation patterns for the proposed reconfigurable antenna in the $x-z, y-z$, and $x-y$ planes are shown in Figure 5, which is conducted at 750, 925, 1925, and $2350 \mathrm{MHz}$. For all the different frequencies, complementary $E_{\varphi}$ and $E_{\theta}$ are observed, which are favorable in practical applications since the position of the mobile handset is unfixed. Some variations are also found, which is largely due to the manufacture tolerance as well as the effects of coaxial cables and the RF switch.

The measured antenna efficiency of the reconfigurable is shown in Figure 6, which is conducted under the consideration of the RF switch. For the lower bands of LTE700/850/900, the antenna efficiency varies in a range of $40 \% \sim 50 \%$, confirming that the introduced RF switch brings acceptable insertion loss for the proposed antenna. For the upper bands of GSM1800/1900/UMTS2100/LTE2300/2500, the antenna efficiency is over $60 \%$. The measured results reveal that the proposed reconfigurable antenna has good radiation characteristics.

\section{Conclusion}

In this paper, a small-size frequency reconfigurable antenna incorporating the one-pole four-throw $\mathrm{RF}$ switch for eight-band mobile handset applications is proposed. The presented reconfigurable antenna is directly printed on the FR4 substrate and occupies a total size of $10 \times 29.5 \mathrm{~mm}^{2}$. By combining the four working states, the operating bands of LTE700GSM850/900/1800/1900/UMTS2100/LTE2300/2500 are successfully covered. According to the measured results, the proposed reconfigurable antenna has good radiation characteristics, which prove that the antenna is applicable for the mobile handset applications.

\section{Conflict of Interests}

The author declares that there is no conflict of interests regarding the publication of this paper.

\section{Acknowledgment}

This work is supported by the National Natural Science Foundation of China (no. 61371108).

\section{References}

[1] K.-L. Wong and T.-J. Wu, "Small-size LTE/WWAN coupledfed loop antenna with band-stop matching circuit for tablet computer," Microwave and Optical Technology Letters, vol. 54, no. 5, pp. 1189-1193, 2012.

[2] Q. Liu, Y. F. Yu, and S. He, "Capacitively loaded, inductively coupled fed loop antenna with an omnidirectional radiation pattern for UHF RFID tags," IEEE Antennas and Wireless Propagation Letters, vol. 12, pp. 1161-1164, 2013.

[3] C.-W. Chiu, C.-H. Chang, and Y.-J. Chi, "Multiband folded loop antenna for smart phones," Progress in Electromagnetics Research, vol. 102, pp. 213-226, 2010.

[4] K.-L. Wong, W.-Y. Chen, and T.-W. Kang, "On-board printed coupled-fed loop antenna in close proximity to the surrounding ground plane for penta-band WWAN mobile phone," IEEE Transactions on Antennas and Propagation, vol. 59, no. 3, pp. 751-757, 2011.

[5] K.-L. Wong, Y.-W. Chang, and S.-C. Chen, "Bandwidth enhancement of small-size planar tablet computer antenna using a parallel-resonant spiral slit," IEEE Transactions on Antennas and Propagation, vol. 60, no. 4, pp. 1705-1711, 2012.

[6] Y.-L. Ban, C.-L. Liu, L.-W. Li, and R. Li, "Small-size wideband monopole with distributed inductive strip for sevenband WWAN/LTE mobile phone," IEEE Antennas and Wireless Propagation Letters, vol. 12, pp. 7-10, 2013.

[7] K.-L. Wong and Y.-C. Liu, "Small-size WWAN tablet computer antenna with distributed and lumped parallel resonant circuits," 
Microwave and Optical Technology Letters, vol. 54, no. 6, pp. 1348-1353, 2012.

[8] C.-H. Ko, K. M. J. Ho, and G. M. Rebeiz, "An electronicallyscanned 1.8-2.1 GHz base-station antenna using package highreliability RF MEMS phase shifters," IEEE Transactions on Microwave Theory and Techniques, vol. 61, no. 2, pp. 979-985, 2013.

[9] M. Abou Al-alaa, H. A. Elsadek, E. A. Abdallah, and E. A. Hashish, "Pattern and frequency reconfigurable monopole disc antenna using PIN diodes and MEMS switched," Microwave and Optical Technology Letters, vol. 56, no. 1, pp. 187-195, 2014.

[10] B. Khalichi, S. Nikmehr, and A. Pourziad, "Reconfigurable SIW antenna based on RF switches," Progress in Electromagnetics Research, vol. 142, pp. 189-205, 2013.

[11] C. G. Christodoulou, Y. Tawk, S. A. Lane, and S. R. Erwin, "Reconfigurable antennas for wireless and space applications," Preceedings of IEEE, vol. 100, no. 7, pp. 2250-2261, 2012.

[12] Y. K. Park and Y. Sung, "A reconfigurable antenna for quad-band mobile handset applications," IEEE Transactions on Antennas and Propagation, vol. 60, no. 6, pp. 3003-3006, 2012.

[13] I. Ben Trad, J. M. Floc'h, H. Rmili, M. Drissi, and F. Choubani, "A planar reconfigurable radiation pattern dipole antenna with reflectors and directors for wireless communication applications," International Journal of Antennas and Propagation, vol. 2014, Article ID 593259, 10 pages, 2014.

[14] Y. Li, Z. Zhang, J. Zheng, Z. Feng, and M. F. Iskander, "A compact hepta-band loop-inverted $\mathrm{F}$ reconfigurable antenna for mobile phone," IEEE Transactions on Antennas and Propagation, vol. 60, no. 1, pp. 389-392, 2012.

[15] H. T. Liu, S. Gao, and T. H. Loh, "Low-cost intelligent antenna with low profile and broad bandwidth," IET Microwave Antenna \& Propagation, vol. 7, no. 5, pp. 356-364, 2013.

[16] S. Baylis, S. Aguilar, and T. Weller, "Wide bandwidth varactortuned patch antenna," Electronics Letters, vol. 45, no. 16, pp. 816$818,2009$.

[17] F. Costa, A. Monorchio, S. Talarico, and F. M. Valeri, "An active high-impedance surface for low-profile tunable and steerable antennas," IEEE Antennas and Wireless Propagation Letters, vol. 7, pp. 676-680, 2008. 

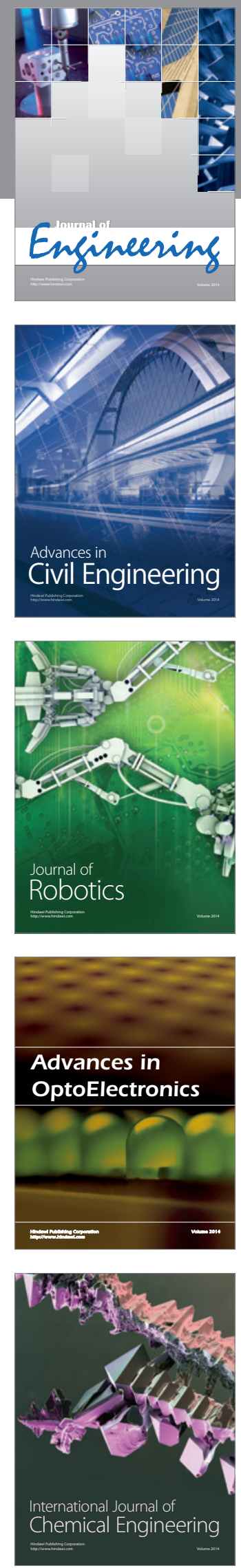

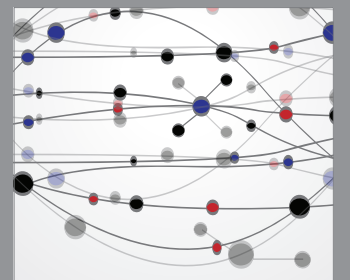

The Scientific World Journal
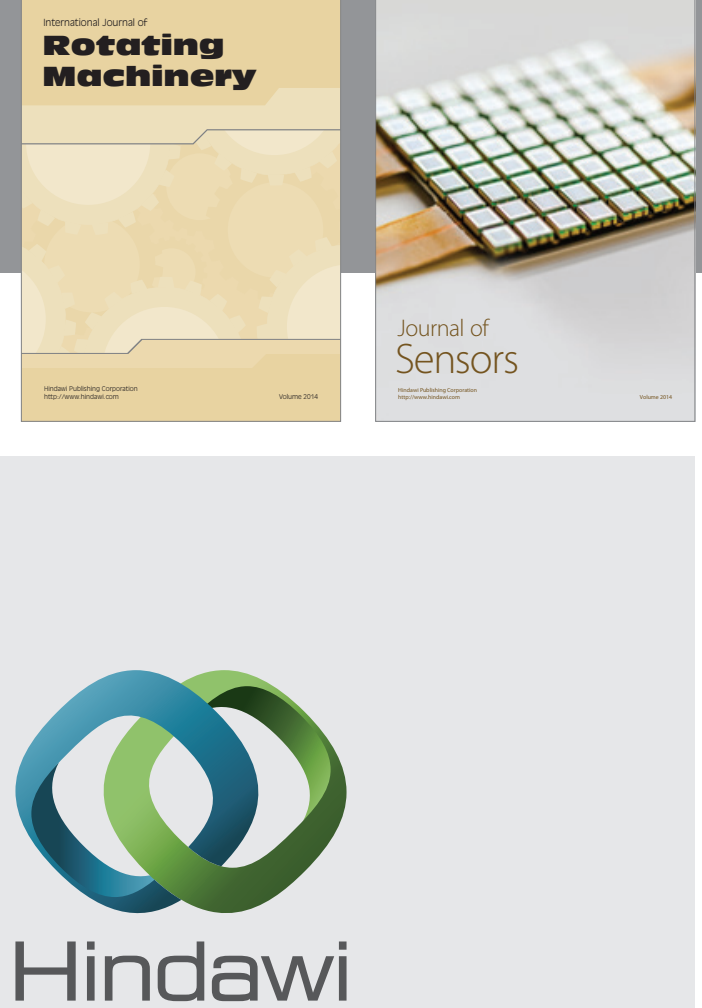

Submit your manuscripts at http://www.hindawi.com
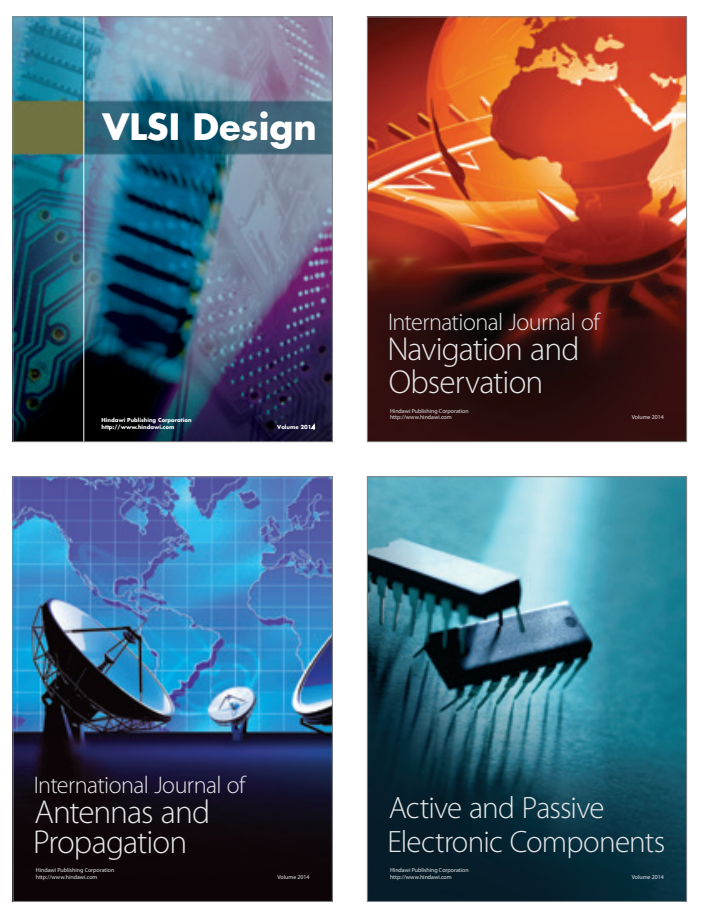
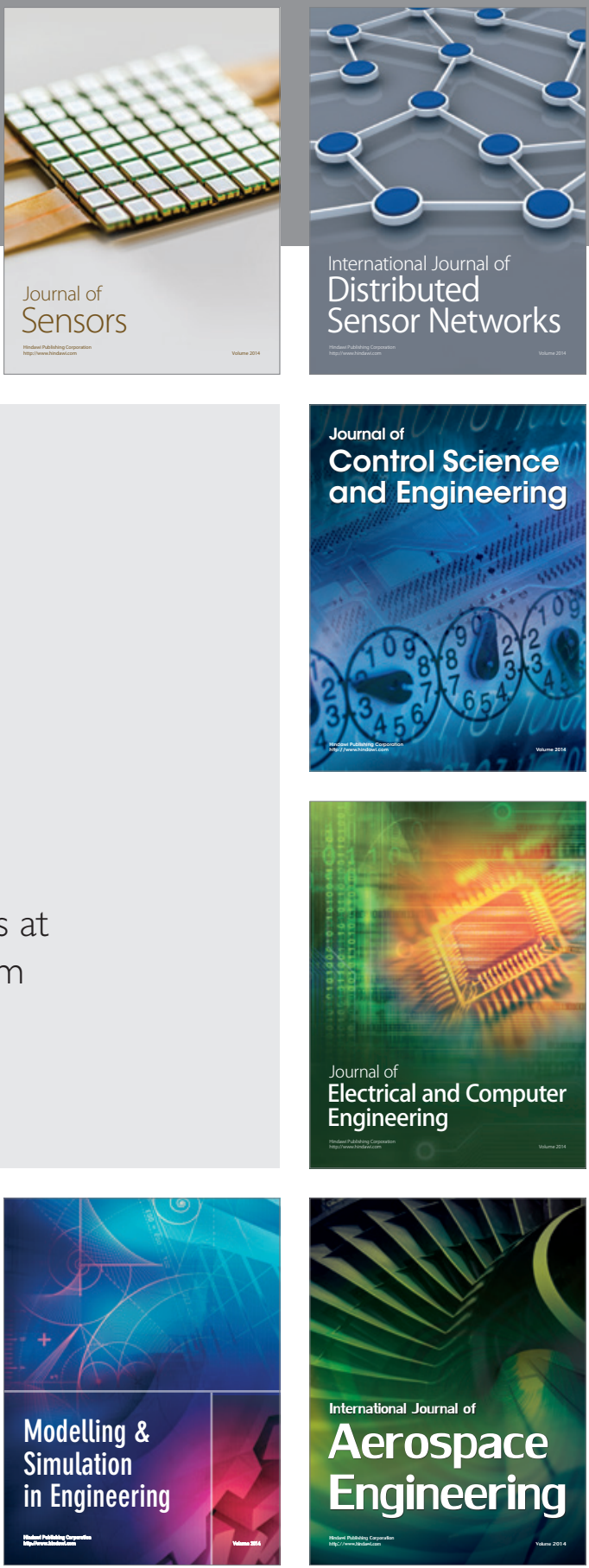

Journal of

Control Science

and Engineering
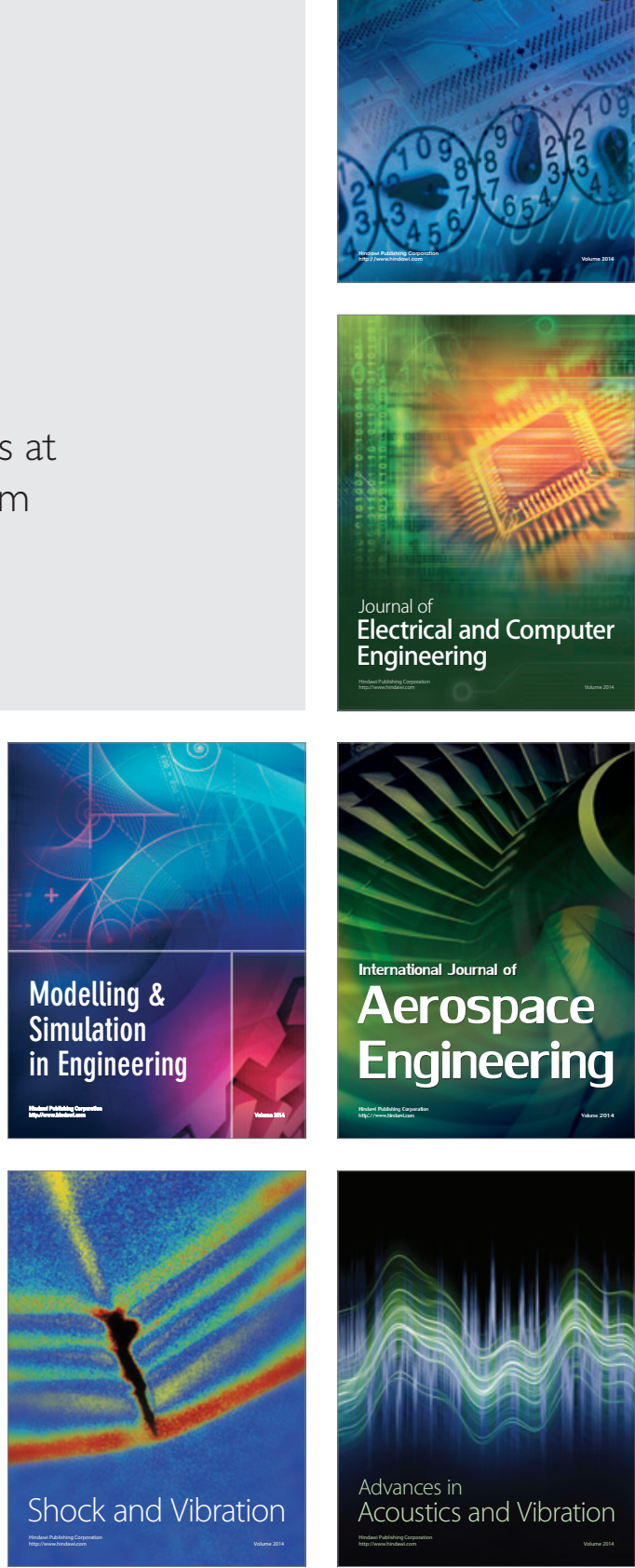